\title{
MODOS DE SER/MODOS DE CRIAR: PERCURSOS DA REFLEXÃO SOBRE A ARTE NA TRILOGIA DA MÃO, DE MÁRIO CLÁUDIO
}

Dalva Maria Calvão Verani Universidade Federal Fluminense

\begin{abstract}
A maneira pela qual a arte é vivenciada pelo homem permite esclarecer sobre a sua essência. A vivência é fonte de autoridade, não apenas para o prazer artístico, como também para a criação. Tudo é vivência.
\end{abstract}

Martin Heidegger*

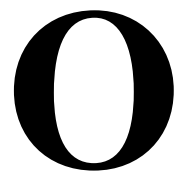

pintor Amadeo de Souza-Cardoso, a violoncelista Guilhermina Suggia e a ceramista Rosa Ramalha, três artistas portugueses nascidos em fins do século XIX, tiveram suas vidas relatadas por Mário Cláudio nos romances Amadeo, Guilhermina e Rosa. O caráter extremamente ambíguo destes relatos, situados em uma linha fronteiriça entre a realidade e a ficção, configura-os como inquestionáveis espaços de reflexão sobre o texto literário, evidenciando a atitude crítica que atravessa toda a obra do autor. Tal atitude crítica, entretanto, não se esgota no questionamento sobre a atividade da escrita, ampliando-se em direção à reflexão sobre a atividade estética de maneira geral, inserindo a obra de Mário Cláudio numa longa tradição, em que se manifesta o interesse de escritores em estabelecer relações entre a palavra escrita e outras manifestações artísticas, permitindo ao texto literário, das mais diferenciadas maneiras, constituir-se como território de diálogo e de reflexão sobre a criação estética em suas

" HEIDEGGER, 1997. p.238. 
múltiplas realizações, bem como de indagação sobre o estatuto daquele que produz a obra de arte. Se, no coerente percurso realizado pelo autor, este interesse pela atividade estética diversificada mantém-se como uma constante, é inegável que, nestes seus romances-biografias, ele se apresenta de modo particular: como já indicia o título emblemático do volume em que se reúnem os três livros - Trilogia da mão -, tais textos se oferecem como intensa possibilidade de reflexão sobre a atividade artística, metonimicamente representada pela mão que trabalha as matérias-primas - as cores e formas para o pintor, os sons para a violoncelista, o barro para a ceramista - em busca de um resultado estético. Dos vários aspectos que assume tal atividade reflexiva, elegemos, neste trabalho, a preocupação evidenciada com as possíveis relações existentes entre maneiras de ser e maneiras de criar.

De fato, seja por uma necessidade de indagar sobre motivações individuais, sobre uma certa disponibilidade para a atividade de criação, seja, numa direção contrária, para evidenciar a inevitável pluralidade de atitudes diante desta mesma atividade, Amadeo, Guilhermina e $R o s a^{1}$ empreendem uma espécie de descrição do modo de ser de cada artista, de uma certa forma de estar na vida que parecerá repercutir em suas produções, constituindo-se, igualmente, como um modo de estar na arte. Surgem, assim, em relação a cada um dos artistas, o desenho de uma vontade, a percepção de traços, talvez observados apenas pelo biográfo, que se mantêm ao longo da trajetória de cada um, configurando-se como uma marca, ou um estilo, em concordância com o que afirma Fayga Ostrower, em sua igualmente dupla condição de artista que pensa sobre o ato de criação:

Cada um de nós só pode falar em nome de suas próprias experiências e a partir de sua própria visão de mundo. E, em sendo cada pessoa um indivíduo único, suas formas expressivas incorporarão, natural e necessariamente, um estilo individual. ${ }^{2}$

\footnotetext{
${ }^{1}$ Nas transcrições feitas no interior do trabalho, tais romances serão identificados pelas iniciais de seu títulos, respectivamente, $A, G, R$.

${ }^{2}$ OSTROWER, 1990. p.251.
} 
Assim, em Amadeo, além de uma aparentemente precoce atenção às formas e cores, ao mundo como espetáculo visual, que se depreende do relato sobre sua infância, apresentada como paisagem constituída por inúmeros elementos plásticos cujo centro é dominado pela casa da família em Manhufe, sobressai a imagem do pintor como artista consciente de sua prória atividade e dos caminhos a trilhar. Avesso a improvisações, guiado por certezas íntimas, Amadeo será apresentado como um ser voluntarioso, "timoneiro de si próprio" $(A, 28)$, racional e exigente, o oposto da imagem de sonhadores Pierrots que pintara quando menino, enganosa pista para quem, "biográfo romântico", aí supusesse "um fado": "Que Pierrot haveria de se converter, como Amadeo, às razões de uma carreira onde tudo se planeou"? $(A, 17)$. Do norte de Portugal a Paris, ultrapassando as estadias por Coimbra e por Lisboa, o pintor de Amarante parece ter tido sempre o domínio sobre si mesmo e sobre o trabalho, a consciência do valor da obra, a determinação para a aprendizagem, a persistência oposta à inspiração fácil, tudo o que, afinal, parece ser a garantia de uma permanência:

Poucas vezes se perderá Amadeo pelas conversas de rua. [...]. A ganância da fama não lhe anulará a reflexão e, quando profetiza que haverão de disputar-lhe os trabalhos a preço de oiro, não o faz pela cegueira da ambição defraudada. É muito menos um vaticínio que o resultado de uma equação para que já dispunha dos termos necessários e suficientes. Pressente-se-lhe nas cartas um pensamento que preexiste à açcão, o que é muito raro nos artistas. Na pintura, também, será a mesma natureza. Digere quanto vê, rabisca ao canto do calendário ilações e memoranda, predispõe-se à aprendizagem sem mestres ungidos, vertiginosa ginástica de se ser e se perder. Não são assim os inspirados, arrebatados por uma águia que nem os arrasa nem os salva. Assim são, porém, os desbravadores de continentes, alguns atletas sem ideologia política, muitos dos artesãos que gravaram siglas na cantaria das catedrais. $(A, 51 / 52)$.

Todo este calculado empenho, contudo, não implica a exclusão da emoção, perceptível à superfície de todas as telas. Tal determinação significa, antes, o controle do não transbordamento, nem na vida, nem na arte, a difícil convivência entre o sentimento 
e sua domesticação: "A escolha que Amadeo realizava, trucidado entre vertigem e programa, reclamava a mobilização das mais remotas energias." ( $A$, 48). E esta mobilização se estendia, inclusive, à organização do espaço externo, à manutenção do "atelier ordenadíssimo" ( $A, 53)$ : "Na desordem da Cité Falguière irritava quem dele se aproximasse, meticuloso até o grotesco, organizandose até a doença $(A, 48)$. Esta atitude de controle, conseqüência de saber-se "um exemplo de vitória" $(A, 48)$, aliada a uma postura de superioridade resultante da consciência de classe, freqüentemente dificultava os contatos e gerava impopularidade, sobretudo no meio dos artistas portugueses igualmente participantes do exílio parisiense, dos quais alguns comentários desfavoráveis ao pintor restaram, como o de Mário de Sá-Carneiro, que o "insultara" de "blaguer e snob" ( $A, 55)$. Amadeo, contudo, avesso sempre à formação de grupos, aos "projetos concertados", em Paris ou de volta a Portugal, mantém a autonomia de seu trabalho, fortificandose "para o prélio na mais total solidão" ( $A$, 98/99). E as marcas de sua personalidade e de sua arte assim produzida serão, algumas vezes, evidenciadas a partir da referência a outros artistas, que, na vida e na obra, pertenceram a outra estirpe, a dos que trabalham a partir do jorro da emoção, nos arriscados limites da paixão. Tal confronto que, em nenhum momento, indicia a excelência de um comportamento sobre o outro, favorece a reflexão sobre as diferentes possibilidades de realização do impulso humano para a arte, ou do "impulso lúdico", como o definiu Schiller. ${ }^{3}$

Neste sentido, a referência a Gaudi, visitado por Amadeo em uma passagem por Barcelona, é, sem dúvida, emblemática. Entre o jovem vindo de Paris e o arquiteto catalão, de sessenta e dois anos, "que só do impulso vindo de uma alucinação voraz derivava a tensão frutificante", uma enorme distância se abre, marcando a diferença dos processos de criação e de seus resultados, guiado, o do espanhol, "como mais uma descoberta das mãos", metáfora da

${ }^{3}$ SCHILLER, 1995. p.83. 
intuição, da desordem admitida, da experiência delirante, em que a inteligência, de acordo com a visão de Amadeo, que nela "se queria praticante", apareceria em posição inferior, no "secundário papel de serviçal da loucura". Ignorando, contudo, o "combate entre especulação e dinâmica do inconsciente", caminho possível para a reflexão sobre suas intrínsicas diferenças, será possível ao pintor estabelecer um elo com o artista de Barcelona, através do fascínio comum pelo efeito prismático da luz, identidade revelada por entre a radical oposição de concepções estéticas: "Mas Gaudi é também náufrago da luz polícroma, ama a refracção dos minerais e a sua faculdade de encaminhar até a cegueira" ( $A, 81 / 82)$.

Semelhante movimento, em que, na recusa fundamental, se instala um ponto em comum, revela-se no contato de Amadeo com a obra de Rimbaud, "um poeta que se queima nas labaredas por ele próprio atiçadas", em tudo oposto ao rigor da disciplina valorizada pelo pintor que, na leitura dos versos "do adolescente roído dos copos e dos camarões", poderia apenas descobrir "outro modo de ser." Entretanto, em meio às óbvias diferenças, existe em ambos, e será isto o que atrairá Amadeo, a celebração da vitalidade, o pendor para "a acção vertiginosa". Apenas, "perante o despenhadeiro", ao contrário do poeta, Amadeo "guarda intactos os órgãos da vista", calculando os riscos, controlando a atenção. Da lição de Rimbaud, é retirada a parte que fascina, por nela ser percebida uma identidade. Em seu constante exercício racional, Amadeo sabe valorizar no outro o que valoriza em si mesmo, mas a relação especular será mediada pelo pensamento, pela lucidez da escolha, pela possibilidade de análise que impede o arrebatamento: por isto, ele "lê Rimbaud como quem pinta" $(A, 93)$.

Tais contrastes entre formas de viver e de criar, propositadamente resgatadas pelo livro para que, pelo jogo de oposições, se esclareçam a personalidade e as opções artísticas do pintor biografado, certamente possibilitariam a retomada da questão nietzschiana sobre impulso apolíneo e impulso dionisíaco, caminhos originais tomados pela Vontade universal, interpretada como potência de criação 
artística. ${ }^{4} \mathrm{Na}$ base das criações estéticas, um dos impulsos sempre dominaria, o que não impediria, muitas vezes, a reunião de ambos, ou um equlíbrio entre eles. Em Amadeo, parece claro o domínio da construção apolínea, da "tendência da energia vital dos desejos e dos sentimentos para se condensar em formas bem delimitadas". ${ }^{5}$ Isto exatamente parece ter reconhecido Eduardo Prado Coelho, ao afirmar que "Mário Cláudio faz, através do exemplo de Amadeo, o elogio do método e a celebração da estratégia criadora." ${ }^{6}$ No mesmo texto, logo a seguir, o crítico transcreve uma passagem do romance em que é reconhecida a distinção entre os dois impulsos básicos mencionados, na referência que o narrador faz a uma possível rejeição à pintura de Amadeo: "E, se a tal um gênio dionisíaco, afogado em pranto ou moscatel, não entender atribuível a qualificação de arte, não será desta lã que as Parcas continuarão a fiar-lhe o fado" $(A, 101)$. Não deixa de ser interessante que, nos fragmentos imediatamente seguintes a esse, o romance apresente as relações a as diferenças entre Amadeo de Sousa-Cardoso e Almada Negreiros, artistas contemporâneos, igualmente defensores e divulgadores das idéias modernistas em Portugal, tão diferentes, contudo, na forma de se conduzirem em relação à carreira e à vida, homens de temperamentos contrários, de cujo confronto mais ressalta a tendência apolínea do pintor de Manhufe, tentado sempre a se esquivar "da ininterrupta alucinação que é o trato com José de Almada-Negreiros" $(A, 101)$. Sem deixar de fazer referência ao conto de Almada dedicado a Amadeo, "K4 O Quadrado Azul", em cuja abertura, literalmente transcrita, o primeiro exalta o pintor de Amarante, definindo-o como "substantivo ímpar 1, o detentor da Apologia Masculina, o que me possui em tatuagem azul na sensibilidade, o Amante preferido da Luxúria e do Vício" ( $A, 102)$, o texto insiste no caráter racional do pintor biografado, em sua

\footnotetext{
${ }^{4}$ NIETZSCHE, 1991. p.7-22.

${ }^{5}$ NUNES, 1989. p.67.

${ }^{6}$ COELHO, 1988. p.80.
} 
opção pelo método, pelo trabalho, pela persistência da procura guiada pela inteligência: "Ele está acima da bebedeira cósmica, e a sua filosofia compele a vida a capitular" $(A, 102)$. Desta forma, apesar do mútuo interesse pela inovação da forma estética, e independente da admiração revelada no conto, que traduz em palavras o resultado subjetivo de uma construção plástica, "não seria Amadeo irmão de Almada, para tanto lhe faltando um proplaso da corrente biológica, um enjoo na viagem dos dias" $(A, 101)$.

Bem diferentes teriam sido os contatos, alguns anos antes, em Paris, entre Amadeo e Amedeo Modigliani, entre os quais "existiam coincidências que não apenas a do onomástico" $(A, 62)$. Para além da origem familiar privilegiada, ou da beleza física, havia a uni-los a mesma decisão de persistência, a mesma rejeição pelo efeito da inspiração superficial, pelos resultados advindos "desses prodígios do acaso, dessa entrega a ninfas e harpias que caracteriza a lenda dos malvados" ( $A, 57)$. Como Amadeo, Modigliani "metodicamente labutava, sem paixão nem pressa, com a exasperação tão-só de quem não reconhece na pujança do próprio corpo efeméride a festejar" $(A, 57)$. Aproximados, portanto, por esta identidade fundamental, a convivência parisiense, à primeira vista fadada ao choque, por possuírem ambos, em partes iguais, "a proa e a contundência" ( $A, 61)$, torna-se possível e amigável, com Amadeo, inclusive, cedendo seu atelier para uma exposição do italiano. A repetida referência a Modigliani, ao invés de contribuir para a percepção de Amadeo pelo que lhe é contrário, funciona, pois, como uma projeção do mesmo, reduplicação de uma imagem a que, a julgar pelo texto, provavelmente não foram alheios os dois artistas, em idêntica oportunidade de contemplação narcísica.

Até que ponto estas diretas ou indiretas caracterizações de Amadeo correspondem inteiramente à verdade, não compete ao texto comprovar, nesta biografia em que a desconfiança ao referencial é constante e em que a parcela de invenção não é pequena. Provavelmente, muito do que o romance revela sobre o pintor corresponde à realidade, ou, ao menos, à visão que dele 
construíram os que o conheceram. Porém, independente de comprovações, o que ressalta de tudo isto é a tentativa de interpretação de um certo modo de ser, a que se liga uma certa forma de manifestação artística, esta, sim, inquestionável. O que se evidencia parece ser, antes de tudo, a preocupação com as possíveis formas de origem e de realização da obra de arte, exposta, igualmente, nas referências aos artistas de tendências diametralmente opostas, revelando o interesse e a enriquecedora curiosidade sobre os territórios subjetivos que orientam o trabalho de criação. A pintura de Amadeo de Sousa-Cardoso, em sua geometria, em seu domínio de formas e de cores, no rigor prismático das composições cubistas, na autonomia plástica dos objetos presentes em algumas colagens, parece, de fato, ligar-se a uma decisão de controle e de método, a uma paciente vontade que rejeita improvisações e desmedidas, ao esforço da inteligência sobre os possíveis exageros da emoção, atendendo, em sua concepção apolínea, "a uma necessidade idêntica à do sonho, cujas imagens, já de acordo com a interpretação de Freud que Nietzsche antecipou, dão forma contida aos impulsos inconscientes e aos desejos reprimidos." 7

Já em Guilhermina, para além da recorrência à idéia de ave, o texto afirmará de várias maneiras seus traços de grande intérprete, apresentando-a sempre em oposição à idéia de acomodação ou de passiva aceitação de regras já estabelecidas. O nariz proeminente e os cabelos insubmissos pareciam, já na meninice, marcar as posições desta artista que, ao contrário de Amadeo, longe estaria de procurar "formas contidas" para a sua expressão. Sem dúvida, para alcançar o domínio sobre o instrumento, muito se terá disciplinado a concertista, como durante o tempo de estudos em Leipzig, onde "pouco mais poderia ver que não fosse a cadência da disciplina, a reverência dela, que é tudo quanto se ganha em estágios assim" $(G, 30)$. Entretanto, um traço de rebeldia será por ela desde o início inserido na execução, como se a disciplina e o domínio da técnica

${ }^{7}$ NUNES, 1989. p.67. 
tivessem como objetivo exatamente libertá-la para a experiência do novo, para a desobediência criadora, em direção oposta ao tranqüilo aprendizado de piano da irmã, sempre submissa ao conselhos do pai, primeiro mestre de ambas: "No ensinamento de Augusto, a infracção principiaria ela a introduzir, insinuando a acrobacia na modulação, a pirueta mesmo, o que as lições ia convertendo em combate de muito fragor" ( $G, 18)$. Das lições com o pai às lições com Pablo Casals, em Espinho - "Que poderia, pois, ensinar-lhe?" ( $G, 25)$-, o que o livro nos mostra é uma artista voluntariosa e apaixonada, pronta a se opor, pouco depois, ao professor alemão Julius Klengel, obediente apenas ao seu próprio modo de interpretar a música: "Como poderia Guilhermina obedecer-lhe, retomar o excerto que lhe fora assinalado, sem todavia prescindir de se ser?" $(G, 29)$. Pelos vários e pessoais caminhos do difícil aprendizado e na tentativa paralela de firmar a própria imagem, Guilhermina, desde logo, "descobrira, inefável pássaro, que jamais nos ensinam os gestos, os ocultos, sobretudo, puríssimos que temos" ( $G, 34)$.

A consciência da própria potencialidade criativa, o assumido exercício da vontade mais íntima, dará a ela, como a Amadeo, o sentimento de uma certa superioridade, o conhecimento de estar cumprindo um caminho de exceção, passível de, ao mesmo tempo, obrigá-la a uma intensa vida pública e a um inevitável sentimentode isolamento. No entanto, se, em Amadeo, tudo contribui para o desenvolvimento do controle e da medida, em Guilhermina, disto resulta o "exacerbamento interpretativo", a "rebeldia à exatidão" $(G, 22)$, a "inquietude" ( $G, 76)$ que, do "gosto hiperbólico" $(G, 23)$ para o vestir, aos "impulsos de actriz desbordada" $(G, 35)$, colecionadora de trajes suntuosos - "Passa, de cenáculo em cenáculo, no vestido de shantung decotadíssimo, com a presilha sobre o umbigo, que é uma enorme mariposa de ametistas" ( $G, 73)$-, passará, ainda, para a prática "do namoro complicado" $(G, 107)$, para o jogo de sedução interminável a que se entrega, numa eterna insatisfação amorosa, que lhe moldará a fama de "vertiginosa, atraindo os homens a caprichosos entrechos, de que logo saudavelmente se esquecia" ( $G, 33)$. "Renitente e selvagem" $(G, 44)$, "destrambelhada" 
$(G, 74)$, possuidora, já na infância, de "reptos de sumptuária rainha" $(G, 12)$, Guilhermina Suggia é revelada como uma artista dionisíaca, que apenas no êxtase da criação interpretativa, na inteira entrega, invocada pela própria relação erótica com o instrumento, transformado em corpo que com paixão é enlaçado, encontra a realização íntima, a saciedade da interminável procura:

Quando os primeiros compassos faz ouvir, com a majestade a que ora protestatários ora submissos os tutti concorrem, estão lançados os dados. Aí se alcandora, assim mesmo querendo que a reconheçam, na estonteadora altura onde o conceito dos outros, bem menos do que indiferente, impeditivo se lhe mostra. Aí se entroniza, ninando o violoncelo, fruste adolescente cujos quadris aperta. Ostenta o vestido de seda roxa, que de Londres trouxe até cá, subido na frente, a desvendar-lhe as meias pretas, os sapatos da mesma cor, de tacão agudo. E é isto, para o auditório portuense, curioso e refastelado, a entrada no bordel rico, através de jarras onde as sécias se desarticulam, num aroma palpitante de cantáridas. Por ela, pelo escândalo que lhes dá, ali mesmo enlouquecem, com Lalo que se desvaira no fecho do terceiro andamento, o frémito dos seios, a selvática madeixa sobre a fronte desabada. $(G, 77)$.

A idéia de escândalo aí evocada parece traduzir adequadamente o trânsito da concertista, o impacto que sua presença possibilitava, ao se transportar, e aos ouvintes, aos espaços absolutos da música, cujo domínio cada vez maior sustentará as ousadias que pratica, recriadora das peças que interpreta, consciente do direito que lhe assiste de instaurar novos sentidos às partituras: "Tocará uma nota adiante da orquestra, o que nela não será excepcional, agora sobretudo, que a idéia a atormenta de esconjurar a perfeição." $(G, 110)$. Em sentido inverso, portanto, à precisão desejada por Amadeo, Guilhermina rejeita o racional, acata a desordem, a imperfeição, a comunhão com forças mais internas e mais subversivas ligadas à emoção e ao conhecimento intuitivo, a cuja manifestação a música serve de meio privilegiado, o veículo por excelência, segundo Nietzsche, para o impulso dionisíaco, para o êxtase, presente nos cantos e danças primitivos, que deram origem à tragédia: 
Que força era essa, que libertava Prometeu de seu abutre e transformava o mito em veículo de sabedoria dionisíaca? É a força heracliana da música: a qual, chegada na tragédia a sua manifestação suprema, sabe interpretar o mito com nova, com a mais profunda imaginação. ${ }^{8}$

Ao propor, portanto, a partir de traços dispersos ao longo dos vários fragmentos dos livros, a reconstrução de possíveis modos de ser de seus biografados, marcas de personalidade e de comportamento, que se refletem nas opções estéticas, na maneira como pensam e vivem a própria expressão, Mário Cláudio não apenas abre caminhos de reflexão sobre as diferenciadas atitudes diante do objeto artístico, como possibilita indagações sobre as potencialidades contidas em diversificadas linguagens, múltiplas formas de contato com o mundo. Ao escolher uma determinada linguagem e ao executá-la de determinada maneira, o artista parece seguir as solicitações de obscura intuição, que parece anterior às influências ou possíveis imposições, ou às oportunidades oferecidas: diante das biografias de Amadeo de Sousa-Cardoso e de Guilhermina Suggia, fica difícil imaginar uma inversão de papéis, de tal forma o perfil de cada um "veste", com propriedade extrema, a linguagem a que se dedicou, principalmente se pensarmos que a ambos, pela camada social a que pertenceram e pela freqüência ao meio urbano, outras possibilidade poderiam ter sido oferecidas. No entanto, cada um optou por aquilo que, com Fayga Ostrower, podemos reconhecer como o "rumo mais apropriado":

Em qualquer trabalho artístico, tanto no âmbito das artes plásticas como no da música, dança, teatro etc., haverá escolhas a serem feitas. Ou seja: dentre numerosos rumos possíveis, o artista escolhe algum que ele sinta como apropriado - todas as outras possibilidade sendo eliminadas, "destruídas" por ora, nesta escolha feita. [...] Quando Picasso diz: "em cada ato criador há um destruidor", ele se refere a esta atitude seletiva, na adequação da linguagem aos conteúdos expressivos. É a seletividade estilística, indispensável ao processo criador.?

${ }^{8}$ NIETZSCHE, 1991. p.11.

${ }^{9}$ OSTROWER, 1990. p.18. 
Em relação a Rosa Ramalha, parece-nos que o mesmo poderíamos dizer da adequação entre seu perfil e sua obra, embora, para ela, a escolha provavelmente se tenha reduzido a duas alternativas: criar com o barro, ou não criar. Se nela, como nos outros, o impulso para a criação se manifesta de maneira acentuada desde muito cedo, o acesso a variadas formas de expressão seria, certamente, impensável. Assim, o que parece acontecer é a conformação de seu desejo à matéria disponível e, num movimento inverso, a imediata conformação desta matéria ao seu modo de ser. Distante tanto do racional rigor de Amadeo, quanta da dramaticidade de Guilhermina, Rosa tem, entretanto, semelhanças com ambos, no que diz respeito à determinação, à persistência e à consciência das "energias que comportava" $(R, 44)$. No entanto, plantada em seu universo próprio, desenvolverá em outra direção as manifestações da subjetividade, toda voltada para a apreensão sensível do mundo que a cerca, unida a ele pelo íntimo contato, que a faz conhecer as coisas pelo caminho primordial do corpo, permitindo-nos pensar em uma atualização "da lição epicurista de que toda gnose começa nos sentidos." ${ }^{10}$ A partir de uma relação telúrica com o seu ambiente, de uma identidade na qual se dá o "comprometimento dos cinco sentidos", ${ }^{11}$ Rosa responde com seu permanente desejo de criação ao apelo da "potência que reside na terra" $(R, 12)$, executando seu trabalho como quem cumprisse um destino, inevitável e aceito, sabendo intuitivamente que apenas assim se encontraria: "E a paz a tomava, porque não conhecia o parto dos artistas em pecado, que, na proximidade de tudo, não sabem adestrar a natureza que têm" $(R, 25)$. De tudo isto resultou uma obra em que poderíamos, tomando de empréstimo algumas das idéias de Bakhtin sobre o texto literário, perceber uma "cosmovisão carnavalesca", pela convivência aí realizada entre vários contrastes, pelo trato familiar que combina "o sagrado com o profano, o elevado com o baixo, o grande com o insignificante, o

${ }^{10}$ MARQUES, 1992. p.292.
${ }^{11}$ MARQUES, 1992. p.292. 
sábio com o tolo, etc", ${ }^{12}$ numa atitude perfeitamente adequada à camada a que pertenceu, de onde, secularmente, surgiram os espaços livres para esta alegre visão de mundo onde as oposições radicais podem ser, ao menos ilusoriamente, excluídas e onde o riso permeia as situações mais inesperadas. A própria Rosa, com suas "chalaças" $(R, 102)$, com sua linguagem desabusada, com a irreverência várias vezes manifestada, com uma certa tendência para a representação, se insere neste mesmo contexto, criando situações próximas ao risível, familiares, contudo, nos ambientes populares das feiras em que se apresentava:

"Ai, senhores, senhores, que tenho o coração da cor da roupinha que trago vestida", declamará ela, a torto e a direito, a avaliar, de olho oblíquo e meio pisco, o efeito do desabafo nas almas caridosas da audiência. Mas nega-lhe a insolúvel consternação aquela banca repleta de bonecos, resultantes do génio desencadeado, policromados todos, sáurios e touros e monstros infernais. [...] À pergunta que lhe dirigem, sobre a vera autoria das ditas obras, invariavelmente responderá, desviada da mágoa que adoptara, "fui eu, ora essa", para logo acrescentar, num arremedo de final esplicação, "com estas mãos que aqui vê." Por dezenas, no berro de seus amarelos e vermelhos e azuis, que um negro categórigo, a espaços, sublinha ou faz contrastar, atestam-lhe as criações o verbo barrento, altaneiras, na permanência de sua maravilha. $(R, 98 / 99)$.

Mesmo o orgulho da produção se manifesta sem nenhuma solenidade, em consonância com a estridência das cores escolhidas, o que, de forma alguma, diminui o reconhecimento, no texto, de sua qualidade, resultado emblemático do "génio desencadeado" de sua autora, ela mesma, no entanto, num movimento oposto à vaidade, capaz de rir do que produz, dessacralizando o próprio talento, pelo reconhecimento do que, para ela, se afigura como uma limitação: "Por detrás das feições sereníssimas, contudo, ia troçando dos próprios artefactos, que sempres se lhe antolhavam processo de desfrute de quanto fora criado à imagem e semelhança de Deus" $(R, 99)$.

${ }^{12}$ BAKHTIN, 1981. p.106. 
Longe da seriedade e da abstração que atravessa as criações dos outros dois artistas, resultante da passagem de seus contatos com a realidade pelo filtro do intelecto, do espírito ou da emoção já elaborada, o que exige a retórica "elevada" de que se servem, a criação de Rosa, em consonância com seu modo de ser, aproxima-se do que, em relação à literatura da Antigüidade, Bakhtin chamou de gêneros do cômico-sério, e que se definiriam por três grandes peculiaridades: primeiro, o tratamento dado à realidade: "a atualidade viva, inclusive o dia a dia, é o objeto ou, o que é ainda mais importante, o ponto de partida da interpretação, apreciação e formalização da realidade." Por esta razão, toda a matéria "séria", os heróis míticos e as personalidade históricas do passado, tradicionalmente tratados pelo distanciamento da forma épica ou trágica, podem ser presentificados e trazidos para o contato familiar. A segunda peculiaridade, que seria inseparável da primeira, é que os gêneros do cômico-sério, ao invés de se basearem na lenda, baseiam-se "conscientemente na experiência e na fantasia livre". E a terceira se configura na "pluralidade de estilos"e na "variedade de vozes", pois tais gêneros "renunciam à unidade estilística da epopéia, da tragédia, da retórica elevada e da lírica. Caracterizam-se pela politonalidade da narração, pela fusão do sublime e do vulgar, do sério e do cômico [...]." 13 Transportados para a análise da cerâmica de Rosa Ramalha, tais peculiaridades parecem ter permanecido intocáveis no tempo, atravessando os séculos da história da arte, para ali se repetirem, incorporadas em outra linguagem estética, originada, como os gêneros mencionados, das manifestações das camadas populares, o que revela a força vital da visão de mundo a que estão associadas tais manifestações: "A cosmovisão carnavalesca é dotada de uma poderosa força vivificante e transformadora e de uma vitalidade indestrutível." ${ }^{14}$ Como os textos do cômico-sério antigos, as cerâmicas de Rosa Ramalha também privilegiam a "atualidade viva",

13 BAKHTIN, 1981. p.93.

${ }^{14}$ BAKHTIN, 1981. p.92. 
seja ela a realidade do dia a dia, na representação e interpretação das coisas que a cercam, ou a realidade do passado, dos mitos, das crenças e das lendas, trazidos para a "zona do contato imediato e profundamente familiar com os contemporâneos vivos", ${ }_{15}^{15}$ na quebra da temporalidade possibilitada pela identidade com esta outra realidade. Como conseqüência desta familiaridade e atualização, a criação da ceramista não se "baseia" na tradição, nem se "consagra"16 através dela, por uma prática de repetição reverencial. Antes, revela a união da tradição com a experiência de vida da artista que, a partir daí, trabalha sua livre fantasia, confeccionando peças em que, por não haver a predominância de uma "unidade estilística", o lírico, o sério, o cômico, o sagrado e o profano podem-se fundir, na apaziguadora convivência relativizadora das imposições racionais.

As referências às ligações da arte de Rosa com estas antigas manifestações originadas das camadas populares e a constatação dos diferenciados resultados entre sua produção e a dos outros artistas da Trilogia, não têm a intenção de responder a indagações sobre diferentes estatutos da produção estética, em classificações que separam o "erudito" do "popular", antes de tudo porque concordamos em que, "no fundo, a designação "popular" ou "erudita" representa apenas um rótulo artificial, que é afixado do lado de fora e nada tem a ver com as genuínas qualidades artísticas da obra." ${ }^{17}$ Além disso, nossa preocupação não é com comparações, muito menos valorativas, entre os diferentes modos de ser, ou entre os resultados do trabalho dos artistas. O que nos interessa é a observação dos processos individuais, a constatação da existência de traços pessoais e culturais que repercutem no trabalho de criação, a evidência do entrelaçamento entre modo de ser, modo de viver e modo de criar. Sem pretensões a qualquer possível reflexão fundada em alguma psicologia da criação, é o próprio mistério desta e a sua inegável individualidade que chama

\footnotetext{
${ }^{15}$ BAKHTIN, 1981. p.93.

${ }^{16}$ BAKHTIN, 1981. p.93.

${ }^{17}$ OSTROWER, 1990. p.253.
} 
nossa atenção nestes romances, onde parecem claras as relações entre o criador e a obra, unidos em um mesmo processo. Mais uma vez valemo-nos das palavras de Fayga Ostrower, aproveitando a coincidência entre o que ela afirma e o que tentamos apontar:

$\mathrm{Na}$ arte, as formas expressivas são sempre formas de estilo, formas de linguagem, formas de condensações de experiências, formas poéticas. [...]. Nelas se fundem a uma só vez o particular e o geral, a visão individual do artista e da cultura em que vive, expressando assim certas vivências pessoais, que se tornaram possíveis em determinado contexto cultural. Ao criar, o artista não precisa teorizar a respeito de suas vivências, traduzir os pensamentos e as emoções em palavras. Ele tem mesmo que viver a experiência e incorporá-la em seu ser sensível, conhecê-la por dentro. Daí, espontaneamente, lhe virá a capacidade de chegar a uma síntese dos sentimentos - naquilo que a experiência contém de mais pessoal e universal - e de transpor esta síntese para uma síntese de linguagem, adequando as formas ao conteúdo. ${ }^{18}$

Deste modo, as criações de Amadeo, de Guilhermina e de Rosa estão impregnadas de suas vivências intransferíveis, das quais, por caminhos nem sempre claros, ou melhor, que não nos cabe procurar esclarecer, resultou a "síntese de linguagem", própria de cada um: a forma voluntariamente cerebral de Amadeo, apolínea construção que reúne o racional e o subjetivo, a geometria e a emoção, numa demonstração do trabalho consciente sobre o espontâneo e obscuro material interno; a sensual interpretação de Guilhermina, dionisíaca entrega à emoção transbordada, ultrapassagem do conhecimento racional do código musical e do domínio técnico do instrumento pela força apaixonada da manifestação sensível; a captação sensorial e fantasiosa de Rosa, lúdica integração à realidade sempre atualizada, num procedimento mágico e primitivo de contato constante com a origens de seu universo.

Tais considerações, por outro lado, não excluem a possibilidade de se pensar a obra de arte em sua existência autônoma, na sua

${ }^{18}$ OSTROWER, 1990. p.17. 
condição de revelar e de significar independentemente do conhecimento sobre as circunstâncias em que foi criada: "justamente onde se desconhece o artista, o processo e as circunstâncias que deram nascimento à obra, esse impulso, esse "que" do ser-criado, vai surgir o mais puramente da obra", afirma Heidegger. ${ }^{19}$ Ao fazer tal afirmação, o filósofo falava da essência da obra, daquilo que se contém na obra realizada e exposta à livre contemplação, à múltipla interpretação:

Quanto mais a obra, identificada em sua forma, permanece recolhida em si-mesma, e mais puramente parece desfazer todas as referências aos homens, tanto mais simplesmente o impulso, pelo qual tal obra é vai manifestar-se no aberto e, mais essencialmente, o insólito vai ser impulsionado para fazer desaparecer o que, até então, parecia o mais habitual. ${ }^{20}$

Quando, porém, se refere à possibilidade de compreensão desta essência, que, por sua vez, poderia explicar o que é a arte, Heidegger se volta para a atividade de criação, para o processo que permite ao artista produzir sua obra:

Entretanto, é evidente que só se pode compreender o ser criado da obra, através do processo da criação. Dessa forma, e por força das coisas, devemos entender que, para chegarmos à origem da obra de arte, devemos considerar a atividade do artista. A própria obra apresenta-se como inviável. ${ }^{21}$

Não nos parece inoportuno trazer aqui esta palavra do filósofo, no sentido de lembrar que os caminhos da reflexão sobre a arte passam também pelas relações entre autor e obra, resgatam a primordial ligação entre eles, procurando, a partir da observação de propósitos diversos, indagar sobre o processo de criação, como faz Mário Cláudio nos romances de sua Trilogia da mão.

\footnotetext{
${ }^{19}$ HEIDEGGER, 1997. p.227.

${ }^{20}$ HEIDEGGER, 1997. p.228.

${ }^{21}$ HEIDEGGER, 1997. p.221.
} 


\section{Referências Bibliográficas}

BAKHTIN, Mikhail. Problemas da poética de Dostoiévski. Rio de Janeiro: Forense-Universitária, 1981.

CLÁUDIO, Mário. Amadeo. Lisboa: Imprensa Nacional/Casa da Moeda, 1984.

CLÁUDIO, Mário. Guilhermina. Lisboa: Imprensa Nacional/Casa da Moeda, 1986.

CLÁUDIO, Mário. Rosa.Lisboa: Impressa Naciona/Casa da Moeda, 1988.

COELHO, Eduardo Prado. A noite do mundo. Lisboa: Imprensa Nacional/Casa da Moeda, 1988.

HEIDEGGER, Martin. A origem da obra de arte. In: DUARTE, Rodrigo (Org.). O belo autônomo. Belo Horizonte: UFMG, 1997.

MARQUES, Maria Theresa Abelha Alves. O nome da rosa é criação. Anais do XIII Encontro de Professores Universitários Brasileiros de Literatura Portuguesa. Rio de Janeiro, UFRJ, p.292-296, 1992.

NIETZSCHE, Friedrich. O nascimento da tragédia no espírito da música. Obras incompletas. 5.ed. São Paulo: Nova Cultural, 1991. (Os pensadores).

NUNES, Benedito. Introdução à filosofia da arte. São Paulo: Ática, 1989.

OSTROWER, Fayga. Acasos e criação artística. Rio de Janeiro: Imago, 1977.

SCHILLER, Friedrich. A educação estética do homem - numa série de cartas. 3.ed. São Paulo: Iluminuras, 1995. 


\section{Resumo}

Este trabalho tem como objetivo analisar um dos aspectos depreendidos da ampla reflexão sobre o fazer estético levada a efeito por Mário Cláudio nos romances de sua Trilogia da mão. Pretendemos evidenciar que, por dentro das recriadas biografias dos três artistas portugueses - Amadeo de SouzaCardoso, Guilhermina Suggia e Rosa Ramalha -, o autor constrói uma delicada rede de relações entre vivências pessoais e culturais e produção estética, instaurando em seu texto a possibilidade para que se repensem as intransferíveis ligações que, em sua origem, unem o artista à sua obra.

\section{Abstract}

The purpose of this work is to analyse one of the aspects inferred from the wide reflection about the aesthetic making done by Mário Cláudio in his Trilogia da mão novels. Also, is its intent to highlight that, inside of the re-created biographies of the three portuguese artists - Amadeo de Souza-Cardoso, Guilhermina Suggia and Rosa Ramalha -, the author builds a delicate net of relations among personal and cultural life experiences and aesthetic production, and establishes in his text the possibility to rethink the untransferable liaisons that, in their origin, unite the artist to his work. 